\title{
Graphene oxide-based microspheres for the dispersive solid-phase extraction of non-steroidal estrogens from water samples
}

\author{
Yingying Wen ${ }^{\mathrm{a}, \mathrm{b}}$, Zongliang $\mathrm{Niu}^{\mathrm{a}}$, Yanling $\mathrm{Ma}^{\mathrm{b}}$, Jiping $\mathrm{Ma}^{\mathrm{c}}$, Lingxin Chen ${ }^{\mathrm{b}, *}$ \\ a Laboratory of Environmental Monitoring, School of Tropical and Laboratory Medicine, Hainan Medical University, Haikou 571199, China \\ ${ }^{\mathrm{b}}$ Key Laboratory of Coastal Environmental Processes and Ecological Remediation, Yantai Institute of Coastal Zone Research, \\ Chinese Academy of Sciences, Yantai 264003, China \\ ${ }^{\mathrm{c}}$ Key Lab of Environmental Engineering in Shandong Province, School of Environment E' Municipal Engineering, Qingdao Technological University, \\ Qingdao 266033, China
}

\section{A R T I C L E I N F O}

\section{Article history:}

Received 12 August 2014

Received in revised form

22 September 2014

Accepted 22 September 2014

Available online 30 September 2014

\section{Keywords:}

Non-steroidal estrogens

Graphene oxide

Dispersive solid-phase extraction

High performance liquid chromatography

\begin{abstract}
A B S T R A C T
A modified Quick, Easy, Cheap, Effective, Rugged and Safe (QuEChERS) method based on the dispersive solid-phase extraction (dSPE) combined with high performance liquid chromatography (HPLC) was developed for the determination of non-steroidal estrogens in water samples. In this study, graphene oxide-based silica microspheres $\left(\mathrm{SiO}_{2} @ \mathrm{GO}\right)$ were used as dSPE material for the preconcentration of analytes. HPLC was used for the separation and detection. This was the first time that the synthesized $\mathrm{SiO}_{2} @ \mathrm{GO}$ microspheres were used as stationary phases for the off-line preconcentration of the non-steroidal estrogens in dSPE. dSPE parameters, such as sample pH, volume and type of eluent were optimized. Application of the developed method to analyze spiked lake, reservoir and tap water samples resulted in good recoveries values ranging from 70 to $106 \%$ with relative standard deviation values lower than $7.0 \%$ in all cases. Limits of detection were in the range of $0.2-6.1 \mu \mathrm{g} / \mathrm{L}$. The combined data obtained in this study recommended that the proposed method is very fast, simple, repeatable and accurate for the detection of non-steroidal estrogens. Furthermore, the $\mathrm{SiO}_{2} @ \mathrm{GO}$ microspheres application could potentially be expanded to extract and pre-concentrate other compounds in various matrices.
\end{abstract}

(c) 2014 Elsevier B.V. All rights reserved.

\section{Introduction}

Estrogens, especially those regulating the differentiation and development of male and female reproductive organs, secondary sex characteristics and behavior patterns, are important biological messengers [1]. Recently, due to the residue in the environment and their potential adverse effects on human health, the estrogens have become a public concerned issue. Studies have proved that the estrogen level in plasma closely relates to the risk of breast cancer. Also, estrogens show toxic and carcinogenic activity even at low levels [2]. Some literature confirmed the presence of estrogens at levels of toxicological concern in aquatic environment [3]. Therefore, an efficient and sensitive method was urgently recommended to monitor estrogens residues in water and thereby ensure the safety of water. Generally, the analytical

\footnotetext{
* Corresponding author. Tel.: +86 535 2109130; fax: +86 5352109130.

E-mail address: lxchen@yic.ac.cn (L. Chen).
}

methods for the determination of estrogens are conducted using high performance liquid chromatography (HPLC) [4-11], gas chromatography [12,13], capillary electrophoresis [14,15], ultra-high performance liquid chromatography [16] and biosensor $[17,18]$. Since the concentration of estrogens is very low in samples, most of the methods mentioned above need sample preparation, such as solid-phase microextraction (SPME) [5,9], solid-phase extraction [6], dynamic liquid-liquid-solid microextraction [7], cloud-point extraction $[8,15]$, dispersive liquid-liquid microextraction (DLLME) [4] and liquid extraction [19,20]. For example, Guan et al. [14] reported the preparation of multi-walled carbon nanotubes (MWCNTs)-OH functionalized magnetic particles and used the functionalized MWCNTs as adsorbents of dispersive solid-phase extraction (dSPE) for extracting estrogens. The LODs of the analytes were from 0.1 to $8.3 \mu \mathrm{g} / \mathrm{kg}$. Pouech et al. [19] reported a Quick, Easy, Cheap, Effective, Rugged, and Safe (QuEChERS) approach to extract testosterone, estrone and $17 \beta$-estradiol in rat testis. In QuEChERS approach, acetonitrile, water and hexane were used as the extraction solvents. Then the pre-concentrated 
estrogens were determined by LC-MS/MS. The LODs of the analytes were from 0.39 to $20.40 \mathrm{ng} / \mathrm{g}$. Scherr and Sarmah [20] developed a liquid extraction method to extract $17 \beta$-estradiol, estrone, $17 \beta$-estradiol-3-sulphate and estrone-3-sulphate in artificial urine solution and agricultural soils. Dichloromethane was the extraction solvent. The LODs of the analytes were from 5.0 to $10.0 \mathrm{ng} / \mathrm{mL}$.

Graphene $(G)$, a two-dimensional honeycomb lattice composed of carbon atoms, has attracted increasing interest for its remarkable mechanical, thermal and electronic properties since 2004 $[21,22]$. As the large delocalized $\pi$-electron system of $G$ can form a strong $\pi$-stacking interaction with the benzene ring $[23,24]$, it might be also a better candidate as an adsorbent to adsorb benzenoid form compounds. Recently, G-based composites have been applied for the extraction of sulfonamide antibiotics [25], protein/peptide [26], neonicotinoid insecticides [27], and pesticide multi-residue [28]. Wang et al. [27] used magnetic graphene nanoparticles as adsorbent to extract neonicotinoid insecticides and then were determined by HPLC. Amine modified graphene was used as reversed-dSPE materials. The pesticide multi-residues were analyzed by LC-MS [28]. However, G sheets have poor solubility in water and organic solvents, owing to the lack of proper functional groups on its surface. On the contrary, graphene oxides (GOs) have rich oxygen contained groups, such as a considerable amount of hydroxyl, epoxide functional groups on both surfaces of each sheet and carboxyl groups mostly at the sheet edges, and are strongly hydrophilic and can form well-dispersed aqueous colloids [29]. Tian et al. [30] prepared $\mathrm{Fe}_{3} \mathrm{O}_{4} @ \mathrm{TiO}_{2} / \mathrm{GO}$ beads and loaded them into a microfluidic chip and used the beads to adsorb estrone, estradiol, and estriol. The estrogens from milk samples were eluted from the beads with methanol and determined by HPLC. Under the optimized conditions, the LODs of the analytes were $4.3-7.5 \mathrm{ng} / \mathrm{mL}$. Although the method showed good results, the whole procedure of chip fabrication was complicated. The good repeatability and reproducibility of the chips were important problems. Therefore, new procedure should be developed. GO was also used as starting coating material that chemically bonded to the fused-silica substrate using 3-aminopropyltriethoxysilane (APTES) as cross-linking agent. Then it was deoxidized by hydrazine to give the graphene coating [31]. In this research, we therefore considered to use GObased silica materials as the sorbents of dSPE.

The "Quick, Easy, Cheap, Effective, Rugged and Safe" (QuEChERS) sample preparation method for determining pesticides in foods was first introduced in 2003 [32]. The method involved miniaturized extraction with acetonitrile, liquid-liquid partitioning and a cleanup step which was carried out by mixing the acetonitrile extract with loose sorbents. Because the sorbent is added to the

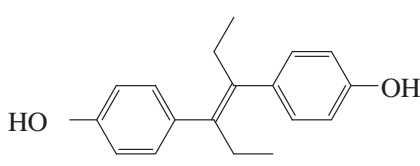

Diethylstilbestrol

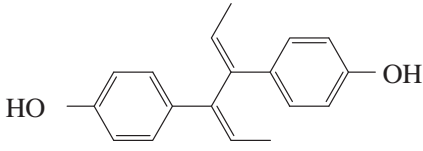

Dienestrol

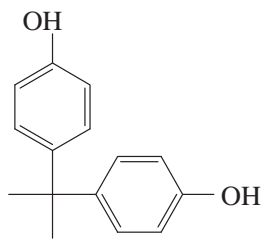

Bisphenol A

Fig. 1. Chemical structures of the estrogens analyzed. bulk solution or matrix containing the analytes, so the possible matrix interferences/components are retained onto it. Thanks to the cleanup step, various elution solvents could be selected. Finally the sorbent was discarded and the elution solvent was analyzed. Therefore, dSPE can be used with the aim of trapping the target analytes which are later eluted or desorbed with an appropriate solvent [33-35].

In our study, graphene oxides were used as coating materials for the preparation of graphene oxide-based silica ( $\mathrm{SiO}_{2} @ \mathrm{GO}$ ) microspheres. Then $\mathrm{SiO}_{2} @ \mathrm{GO}$ microspheres were used as the sorbents in dSPE for extracting non-steroidal estrogens. After extracted in dSPE, the estrogens were analyzed by HPLC. To the best of our knowledge, this was the first demonstration for $\mathrm{SiO}_{2} @ \mathrm{GO}$ microspheres as dSPE sorbents to extract non-steroidal estrogens. dSPE coupled with HPLC method was developed, validated and successfully applied for simultaneous separation and determination of several non-steroidal estrogens in water samples.

\section{Experimental}

\subsection{Chemicals, standard solutions and water samples}

Graphene oxide was purchased from Nanjing XFNano Materials Technology Company (Nanjing, China). Three non-steroidal estrogen standards of diethylstilbestrol (DES), dienestrol (DS) and bisphenol A (BPA) were purchased from Sigma-Aldrich (Shanghai, China), and their chemical structures are shown in Fig. 1. Tetraethyl orthosilicate (TEOS) and APTES were purchased from Aladdin Chemistry Co., Ltd. (Shanghai, China). Chromatographic grade acetonitrile $(\mathrm{ACN})$ and methanol $(\mathrm{MeOH})$ were purchased from J\&K Chemical (Beijing, China). All other chemicals, such as ethanol $(\mathrm{EtOH})$, ammonia, sodium hydroxide $(\mathrm{NaOH})$, sodium dihydrogen phosphate $\left(\mathrm{NaH}_{2} \mathrm{PO}_{4}\right)$, and phosphoric acid $\left(\mathrm{H}_{3} \mathrm{PO}_{4}\right)$ were all of analytical grade and attained from Sinopharm Chemical Reagent (Shanghai, China). Water used throughout the work was produced by a Milli-Q Ultrapure water system (Millipore, Bedford, MA, USA).

Stock solutions containing $1000 \mu \mathrm{g} / \mathrm{mL}$ of each estrogen were prepared by dissolving the required amounts of the standards in $\mathrm{MeOH}$. Working solutions were prepared by diluting the stock solutions with appropriate amounts of water. They were stored in a refrigerator at $4{ }^{\circ} \mathrm{C}$ for use.

Lake water and reservoir water were collected from a reservoir and an artificial lake located in Laishan District of Yantai City (China) and stored in the dark at $4{ }^{\circ} \mathrm{C}$ for use. Tap water was collected after flowing for about $5 \mathrm{~min}$ in the laboratory when needed. Before use, the samples were passed through microporous nylon filters with the pore sizes of $0.45 \mu \mathrm{m}$ in diameter. Several aliquots from $10 \mathrm{~mL}$ filtered water samples were spiked with the estrogen standards of different concentrations, followed by dSPE procedure.

\subsection{Apparatus}

An HPLC instrument was provided by Skyray Instrument Inc. (Kunshan, Jiangsu, China), equipped with a UV detector. Separation was carried out on a Waters Arcus EP-C18 column ( $250 \mathrm{~mm} \times 4.6 \mathrm{~mm}$ id, $5 \mu \mathrm{m}$ particle size). Analytes were eluted by a mixture of $\mathrm{ACN}$ and water. The gradient elution program

Table 1

Gradient elution program of columns.

\begin{tabular}{lll}
\hline Time $(\min )$ & $\mathrm{ACN}(\%)$ & $\mathrm{H}_{2} \mathrm{O}(\%)$ \\
\hline 0 & 60 & 40 \\
1 & 60 & 40 \\
5 & 40 & 60 \\
10 & 40 & 60 \\
\hline
\end{tabular}




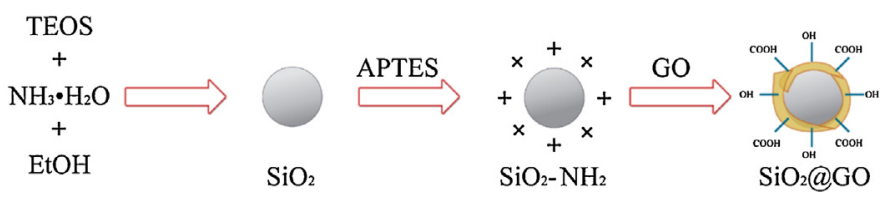

Fig. 2. Synthesis of $\mathrm{SiO}_{2} @ G O$ microspheres.

was shown in Table 1. Non-steroidal estrogens were monitored at $230 \mathrm{~nm}$ and the sample injection volume was $20 \mu \mathrm{L}$. All the samples were passed through microporous nylon filters of $0.45 \mu \mathrm{m}$ pore sizes in diameter (Pall Corporation, USA). Scanning electron microscopy (SEM) images were conducted by an S-4800 SEM instrument (HITACHI, Japan) operating at $20 \mathrm{kV}$. All samples were sputter-coated with gold before SEM analysis. Transmission electron microscopy (TEM) images were obtained by a JEM-1230 electron microscope (JEOL, Ltd., Japan) operating under $100 \mathrm{kV}$ accelerating voltage. IR spectra were done on a NICOLET iS 10 Fourier transform infrared (FT-IR) spectrometer (Thermo Fisher, USA).

\subsection{Synthesis and characteristics of $\mathrm{SiO}_{2} @ G O$ microspheres}

The overall synthetic procedure is depicted in Fig. 2 and involving the following three steps. (a) $\mathrm{The}^{\mathrm{SiO}_{2}}$ microspheres were synthesized by using classic Stöber ammonia base-catalyzed hydrolysis method [36]. Eight milliliters ammonia and fifty milliliters EtOH were added into a $150 \mathrm{~mL}$ flask and followed by stirring. Then $8 \mathrm{~mL}$ TEOS was added to the flask by a constant pressure dropping funnel at a flow rate of $1 \mathrm{~mL} / \mathrm{min}$. After stirring for $24 \mathrm{~h}$, the microspheres were taken out, washed with EtOH and water thoroughly for three times and finally dried in air, powdered to particles. (b) The microspheres were further functionalized with APTES to make the particles positively charged. Six milliliters of APTES were added to a $50 \mathrm{~mL}$ stirred suspension of the starting gel ( $5 \mathrm{~g}$ of $\mathrm{SiO}_{2}$ microspheres) in refluxing toluene for $2 \mathrm{~h}$. After the mixture was slowly cold, the solid phase was recovered by filtration and washed with fresh toluene. It was then heated at $120^{\circ} \mathrm{C}$ for $12 \mathrm{~h}$ and finally powdered to particles [37]. (c) The negatively charged GO sheets were assembled on the amino-functional silica microspheres through electrostatic interactions. The positive microspheres were added into the $0.2 \mathrm{wt} . \%$ aqueous GO dispersion for $24 \mathrm{~h}$ in a $70^{\circ} \mathrm{C}$ water bath. Then, they were taken out and heated at $120^{\circ} \mathrm{C}$ for $12 \mathrm{~h}$ and finally powdered to particles. The product was denoted as $\mathrm{SiO}_{2} @ \mathrm{GO}$ microspheres.

The size and shape of the products were examined by TEM and SEM. The surface functional groups were analyzed by FT-IR.

\section{4. dSPE procedure}

Ten milliliters of spiked sample (spiked concentrations of DES, DS and BPA were $2,0.2$ and $1 \mu \mathrm{g} / \mathrm{mL}$, respectively) was adjusted to $\mathrm{pH} 6.0$ and transferred to a flask containing $20 \mathrm{mg} \mathrm{SiO}{ }_{2} @ \mathrm{GO}$ microspheres. The mixture was extracted for $40 \mathrm{~min}$ under ultrasonic bath at $40^{\circ} \mathrm{C}$. Subsequently, it was centrifuged for $5 \mathrm{~min}$ at $9000 \mathrm{rpm}$. The upper water phase was discarded. Then the mixture was desorbed for $40 \mathrm{~min}$ by $100 \mu \mathrm{L}$ ACN under ultrasonic bath at $40^{\circ} \mathrm{C}$ and centrifuged for $5 \mathrm{~min}$ at $9000 \mathrm{rpm}$. Finally, ACN layer was filtered through a $0.45-\mu \mathrm{m}$ filter membrane and was analyzed by HPLC. The whole extraction process is shown in Fig. 3.

\section{Results and discussion}

\subsection{Characterization of $\mathrm{SiO}_{2} @ G O$ microspheres}

To investigate the morphology and structure of the $\mathrm{SiO}_{2} @ \mathrm{GO}$ microspheres, the SEM and TEM images are shown in Fig. 4a and b. It can be seen from Fig. 4 that the microspheres with a size of about $200-300 \mathrm{~nm}$ are well distributed and tightly encapsulated by corrugated and ultrathin GO sheets.

Fig. 4c shows the FT-IR spectra of GO. The most characteristic features were the adsorption bands corresponding to the $\mathrm{C}=\mathrm{O}$ of carboxyl, stretching at $1629 \mathrm{~cm}^{-1}$, the $\mathrm{C}-\mathrm{OH}$ stretching of epoxide group at $1107 \mathrm{~cm}^{-1}$ and $\mathrm{O}-\mathrm{H}$ stretching vibrations of the water appeared at $3410 \mathrm{~cm}^{-1}$ as broad adsorption bands.

All the above results demonstrated the successful synthesis of $\mathrm{SiO}_{2} @ \mathrm{GO}$ microspheres.

\subsection{Optimization of the dSPE conditions}

As a QuEChERS method, dSPE is a popular optimal alternative. GO materials have been considered as excellent sorbents because of their well-dispersed aqueous solubility, large surface area and high affinity toward various organic compounds. In order to select the optimal dSPE conditions for the extraction of the non-steroidal estrogens, $20 \mathrm{mg} \mathrm{SiO}_{2} @ \mathrm{GO}$ microspheres and $10 \mathrm{~mL}$ water samples were used to study the extraction performance of the dSPE under different experimental conditions. In this experiment, several parameters, including sample $\mathrm{pH}$, the extracting temperature and time for adsorption, and desorption conditions were investigated to achieve the best extraction efficiency for the non-steroidal estrogens.

\subsubsection{Effect of sample $\mathrm{pH}$}

Since non-steroidal estrogens are amphoteric compounds, their molecular status was affected by sample $\mathrm{pH}$. Therefore, sample $\mathrm{pH}$ would dramatically affect the extraction efficiency. The $\mathrm{pH}$ optimization was performed in $20 \mathrm{mM}$ phosphate buffer solution over the range from 4.0 to 8.0. As shown in Fig. 5a, there was no obvious variation of extraction efficiency for DS under $\mathrm{pH}$ ranging from 4.0 to 6.0 . The extraction efficiency was the highest when $\mathrm{pH}$ was 6.0. Then the efficiency decreased a little when $\mathrm{pH}$ exceeded 6.0. As for DES, extraction efficiency decreased rapidly at $\mathrm{pH}$ greater than 6. However, extraction efficiency for BPA increased during the tested $\mathrm{pH}$. This phenomenon may be caused by different molecular status of the analytes. The $\mathrm{pK}_{\mathrm{a}}$ values for DES, DS and BPA were 7.34, 7.43 and 10.3, respectively [15,38]. For DES and DS, when sample pH was lower than 6.0 , they were neutral molecular, the analytes showed high affinity with GO through hydrophobic interaction; when $\mathrm{pH}$ increased above 6.0 , they were deprotonated and showed affinity with sample matrix. In such a case, the hydrophobic interaction would be suppressed, so the extraction efficiency was lower. Although the extraction efficiency increased in the tested $\mathrm{pH}$ range for BPA, the variety was not evident. BPA was neutral molecular when sample pH was 6.0, it showed high affinity with GO. Therefore, sample matrix was adjusted at $\mathrm{pH} 6.0$ in the following experiments.

\subsubsection{Effect of extraction and desorption temperature}

In general, increasing the extraction temperature can enhance mass transfer of analytes from water to the $\mathrm{SiO}_{2} @ \mathrm{GO}$ microspheres or from the $\mathrm{SiO}_{2} @ \mathrm{GO}$ microspheres to the desorption solution, thereby increasing extraction efficiency of dSPE.

The effect of extraction temperature was tested within a range of $20-70^{\circ} \mathrm{C}$. As shown in Fig. 5b, the extraction efficiency increased with the temperature increasing within the range of $20-40^{\circ} \mathrm{C}$ and then decreased when the temperature was over $40^{\circ} \mathrm{C}$ for DES and 

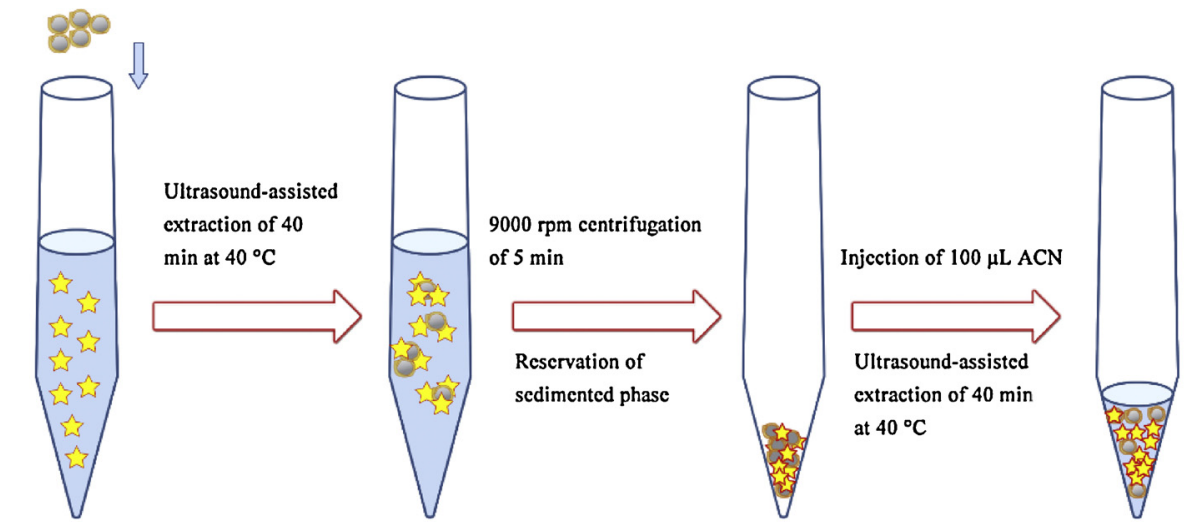

Water sample

Cloudy solution

$\mathrm{SiO}_{2} @ \mathrm{GO}$ particals

Cloudy solution

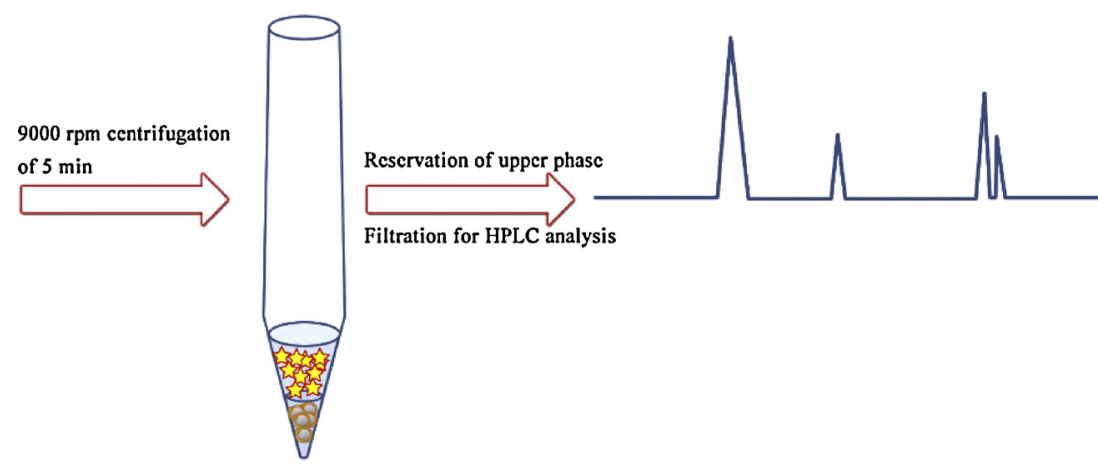

Analytes solution and $\mathrm{SiO}_{2} @ G O$ particals

$\mathrm{SiO}_{2} @ \mathrm{GO}$ partical

Fig. 3. Schematic illustration of the dSPE procedure.

Table 2

Linear calibration ranges, regression equations and limits of detection of the three analytes.

\begin{tabular}{lllll}
\hline Analytes & Linear range $(\mu \mathrm{g} / \mathrm{L})$ & Regression equation & $r$ & $\mathrm{LOD}(\mu \mathrm{g} / \mathrm{L})$ \\
\hline BPA & $10-2000$ & $A=8748.7 C+258.98$ & 0.9994 & 3.0 \\
DES & $20-2000$ & $A=8745.4 C+157.95$ & 0.9996 & 6.1 \\
DS & $0.5-2000$ & $A=44,791 C+3478.3$ & 0.9988 & 0.2 \\
\hline
\end{tabular}

DS. This might be attributed to the heat unstability of phenolic hydroxyl groups in non-steroidal estrogens [15]. The phenolic hydroxyl group could be changed into quinone or other structure under high temperature. And the extraction efficiency increased with increasing temperature for BPA. Combined with the obtained data suggested that, in order to obtain high extraction efficiency for all the analytes, the extraction temperature of $40^{\circ} \mathrm{C}$ was chosen for the following experiments.

The effect of desorption temperature was also tested within the range of $20-70^{\circ} \mathrm{C}$. As shown in Fig. 5c, the extraction efficiency increased with the temperature within the range of $20-40^{\circ} \mathrm{C}$, and then decreased when the temperature was over $40^{\circ} \mathrm{C}$. So, $40^{\circ} \mathrm{C}$ was selected as the desorption temperature.

\subsubsection{Effect of extraction and desorption time}

The extraction time profile was investigated over the range of $10-60 \mathrm{~min}$. As shown in Fig. 5d, the highest extraction efficiency was obtained when the extraction time was $40 \mathrm{~min}$. So, 40 min was selected as the extraction time. Different desorption time showed no significant influence on the extraction efficiency (as shown in Fig. 5e), thus 40 min was selected as desorption time.
Table 3

Recovery and precision (SD) of analytes from tap, reservoir and lake water samples.

\begin{tabular}{lllrl}
\hline \multirow{2}{*}{ Analytes } & Added $(\mu \mathrm{g} / \mathrm{L})$ & \multicolumn{3}{l}{ Recovery, mean $\pm \mathrm{SD}(\%)$} \\
\cline { 3 - 5 } & & Tap water & Reservoir water & Lake water \\
\hline \multirow{2}{*}{ BPA } & 10 & $71 \pm 5.8$ & $78 \pm 6.9$ & $70 \pm 6.6$ \\
& 20 & $78 \pm 3.5$ & $102 \pm 2.4$ & $78 \pm 3.0$ \\
\multirow{2}{*}{ DES } & 50 & $96 \pm 1.7$ & $82 \pm 2.0$ & $74 \pm 1.4$ \\
& 10 & $90 \pm 4.6$ & $85 \pm 3.5$ & $85 \pm 5.1$ \\
& 20 & $87 \pm 2.0$ & $94 \pm 1.9$ & $87 \pm 3.2$ \\
DS & 50 & $98 \pm 1.4$ & $96 \pm 3.0$ & $106 \pm 1.1$ \\
& 10 & $83 \pm 6.0$ & $89 \pm 5.3$ & $100 \pm 4.9$ \\
& 20 & $95 \pm 2.8$ & $97 \pm 1.2$ & $95 \pm 2.0$ \\
& 50 & $94 \pm 1.9$ & $90 \pm 2.1$ & $94 \pm 2.7$ \\
\hline
\end{tabular}

\subsubsection{Effect of desorption solution}

Three solvents including $\mathrm{MeOH}, \mathrm{ACN}$ and EtOH were studied as desorption solution. Desorption capabilities of these solvents are depicted in Fig. 5f. It can be seen that $\mathrm{ACN}$ provided the best desorption capability under the same extraction and elution conditions. Therefore, ACN was selected as the desorption solution.

\subsection{Analytical performance of dSPE-HPLC}

Method performance of the optimized dSPE was evaluated by HPLC. Quantitative parameters such as linear range, correlation coefficients, and limits of detection (LODs) were evaluated. Linear correlation coefficients $(r)$ assessed at six different concentration levels were obtained between peak-area and the corresponding 

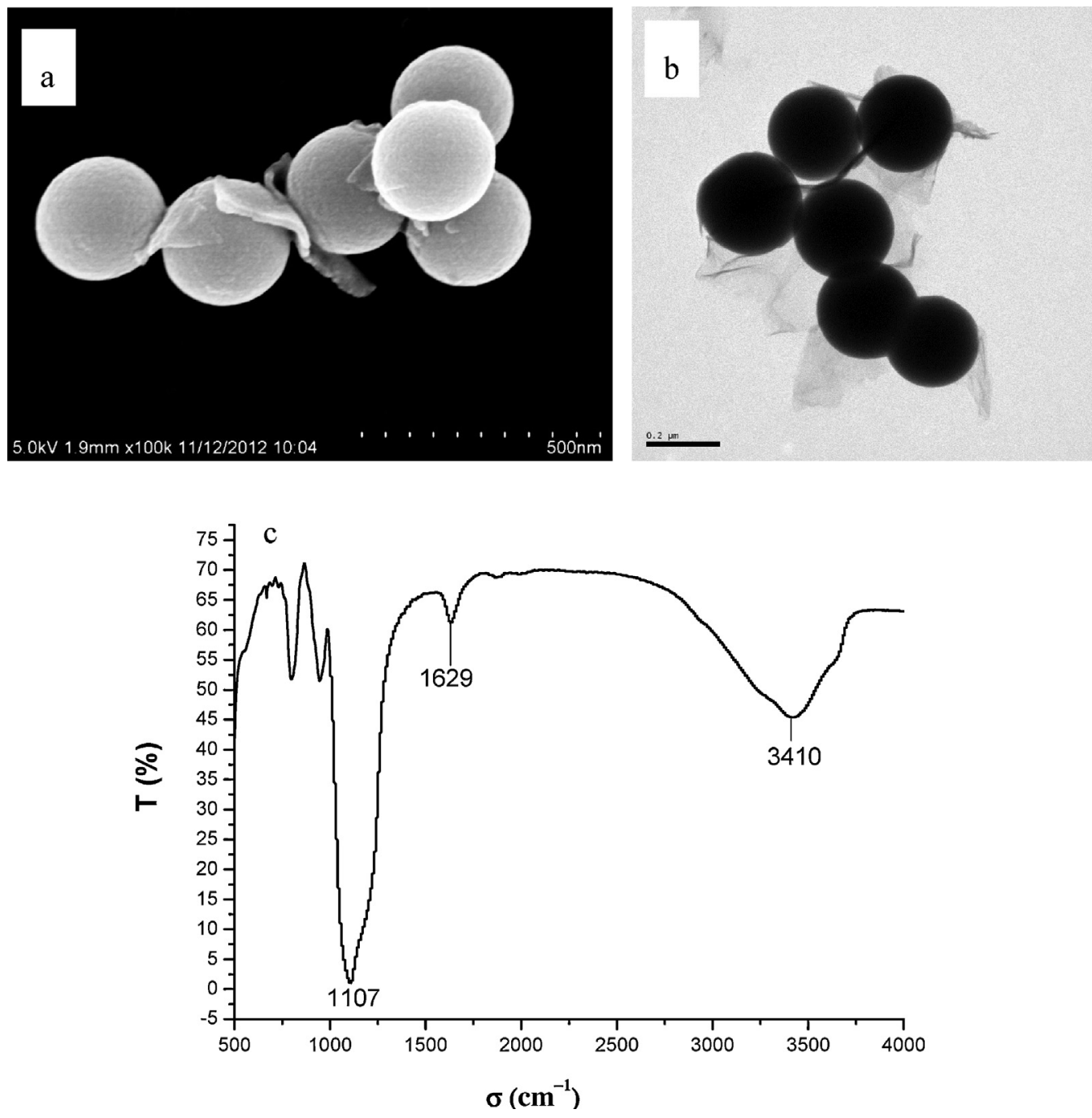

Fig. 4. SEM, TEM and IR images of $\mathrm{SiO}_{2} @ G O$ microspheres.

concentrations of non-steroidal estrogens in the range from 0.5 to $2000 \mu \mathrm{g} / \mathrm{L}$ are listed in Table 2. LODs for all the three non-steroidal estrogens, calculated as the analyte concentration for which the peak height was three times the background noise $(3 \mathrm{~S} / \mathrm{N})$, were attained $0.2,3.0$ and $6.1 \mu \mathrm{g} / \mathrm{L}$ for DS, BPA and DES, respectively (Table 2).

\subsection{Analysis of environmental water samples}

In order to validate the potential application of the developed method in the natural samples, the method was applied to lake, reservoir and tap water. Before the spiking procedure, the samples were analyzed and were found to be free of non-steroidal estrogens

Table 4

Performance comparisons for estrogens determination with other reported QuEChERS analytical methods.

\begin{tabular}{|c|c|c|c|c|c|c|}
\hline Detection technique & Pretreatment method & Sample & $\mathrm{LOD}(\mathrm{ng} / \mathrm{mL})$ & Linear range $(\mu \mathrm{g} / \mathrm{L})$ & Recovery (\%) & Ref. \\
\hline HPLC-FD & DLLME $^{\mathrm{a}}$ & Surface and waste water & $2.0-6.5 \mathrm{ng} / \mathrm{L}$ & - & $98-106$ & [4] \\
\hline HPLC-UV & Magnetic SPE & River water & $3.2-20.1 \mathrm{ng} / \mathrm{L}$ & $0.1-100 \mathrm{mg} \mathrm{L}^{-1}$ & $85.5-103.7$ & [6] \\
\hline HPLC-UV & DLLSME $^{\mathrm{b}}$ & Tap water & $0.05-0.48$ & $0.25-100$ & $81.9-99.8$ & [7] \\
\hline HPLC-DAD & $\mathrm{CPE}^{\mathrm{C}}$ & Human urine & $0.1-0.2$ & 5-1000 & $85.35-104.03$ & [8] \\
\hline HPLC-UV & SPME $^{\mathrm{d}}$ & Milk & 5.1 & $24-960$ & $57.50-120.42$ & [9] \\
\hline HPLC-MS/MS & Liquid extraction & Rat testes & $1.81-6.94 \mathrm{ng} / \mathrm{g}$ & $2.95-576 \mathrm{ng} / \mathrm{g}$ & $101-110$ & [19] \\
\hline HPLC-MS & Liquid extraction & $\begin{array}{l}\text { Artificial urine solution and } \\
\text { agricultural soils }\end{array}$ & $5.0-10$ & $10-1000$ & $41.3-100$ & [20] \\
\hline HPLC-UV & dSPE & Lake, reservoir and tap water & $0.2-6.1$ & $0.5-2000$ & $70-106$ & This work \\
\hline
\end{tabular}

\footnotetext{
a Dispersive liquid-liquid microextraction.

b Dynamic liquid-liquid-solid microextraction.

c Cloud-point extraction.

d Solid-phase microextraction.
} 

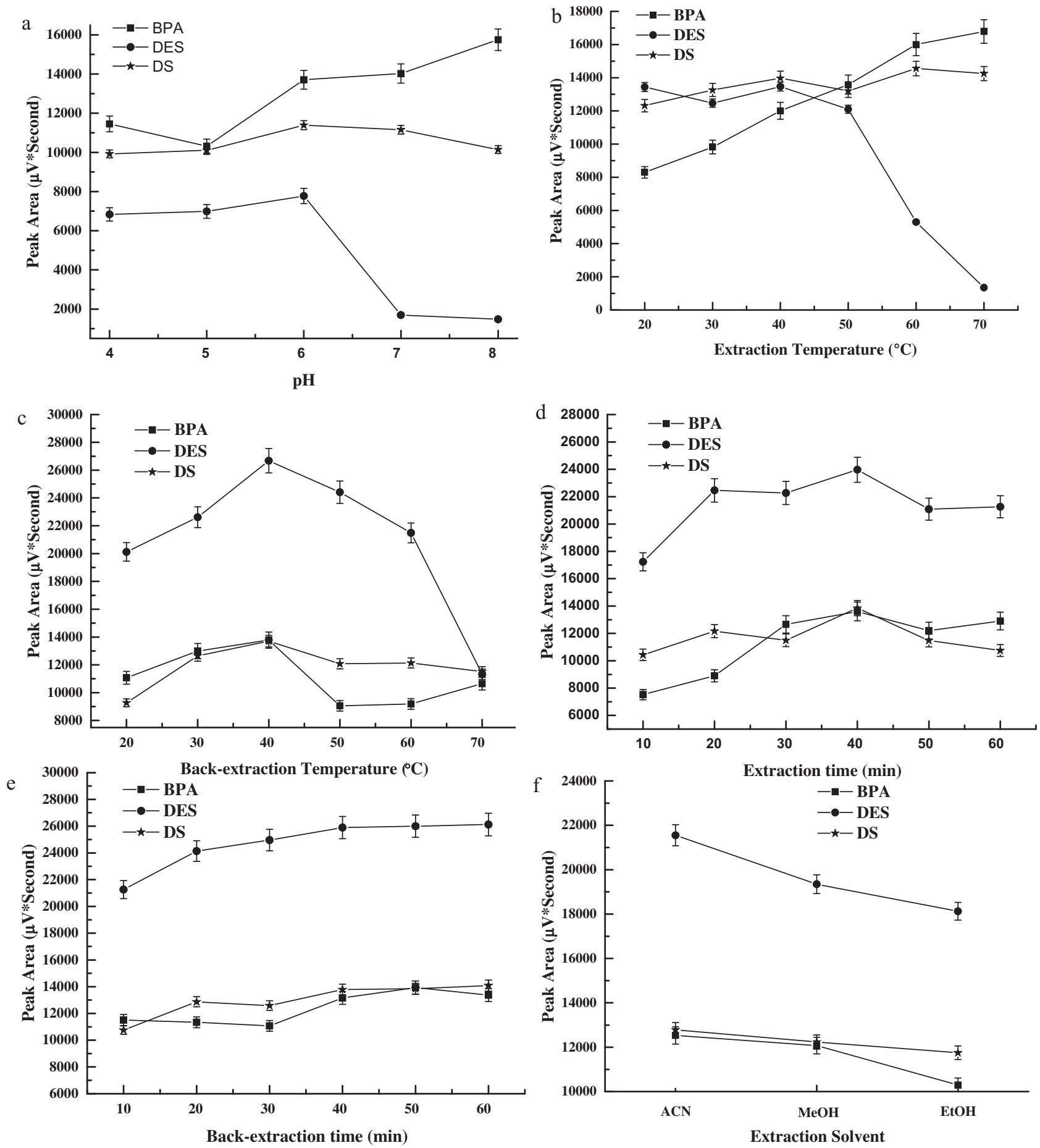

Fig. 5. Selection of optimal dSPE extraction conditions.

contamination. Typical chromatograms of the three water samples before and after spiking are shown in Fig. 6 . The recoveries of the non-steroidal estrogens were studied by spiking the non-steroidal estrogens standard solution into water samples at three concentrations $(10,20$ and $50 \mu \mathrm{g} / \mathrm{L})$ in different samples spiked that were from 70 to $106 \%$ with the relative standard deviations (RSDs) of $1.1-6.9 \%$ (Table 3 ).

\subsection{Method performance comparison}

Analytical performances of the developed QuEChERS methods for the detection of non-steroidal estrogens were mainly compared with the previously HPLC hyphenated techniques. As can be seen from Table 4, some of the reported methods provided higher sensitivity for estrogens than the present method [4-8]. Nevertheless, in a sense, they are also involved in complex enrichment procedures, long time-consuming procedures, or high-cost procedures. For example, an on-line DLLSME-HPLC method [7] for the extraction of the estrogens, the procedure for the whole process of on-line system setup, was complicated and needed a long time for the preparation of molecularly imprinted polymer filaments (MIPFs) as solid phase. The other methods [19] and [20] needed some organic solvents such as hexane and dichloromethane. Moreover, our method showed wider linear range than the other methods. The 

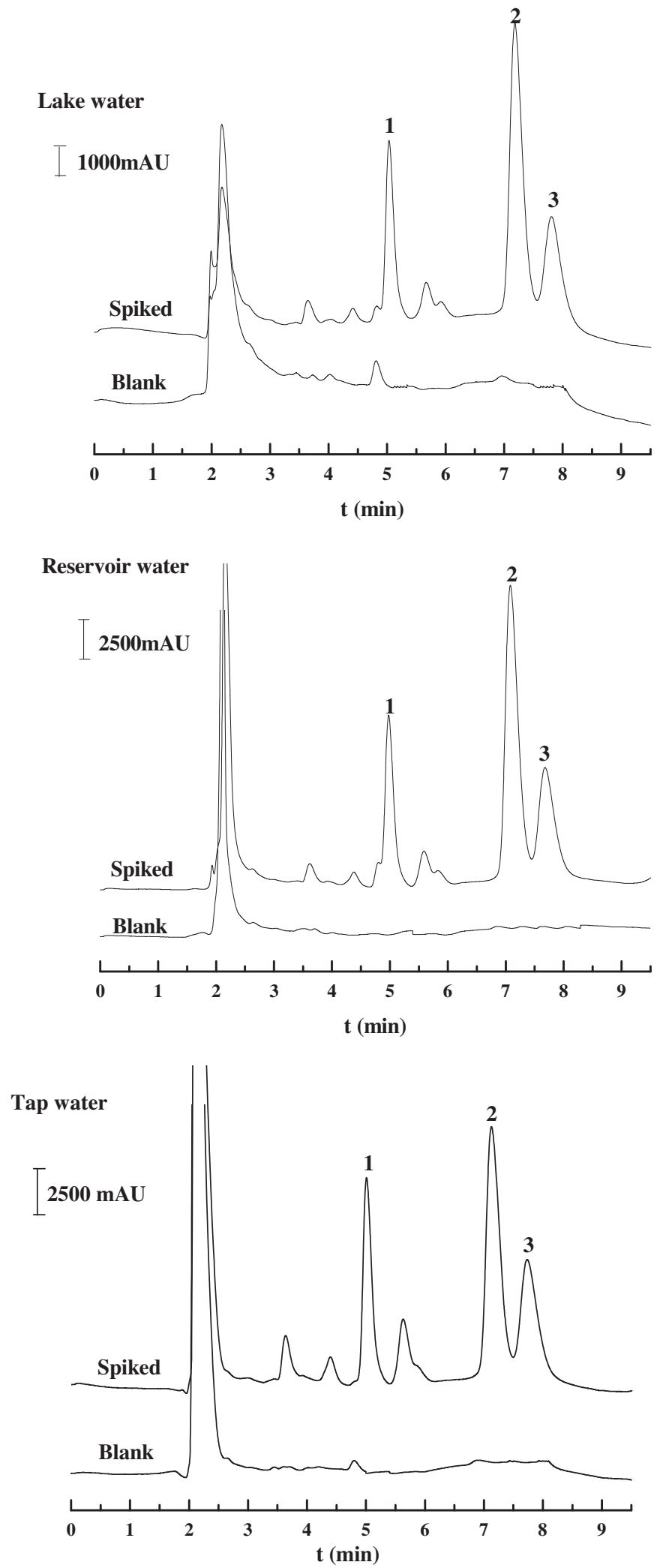

Fig. 6. Typical dSPE-HPLC-UV chromatograms of spiked and non spiked water samples 1 - BPA, 2 - DES, 3 - DS, and the spiked concentration of each estrogen were 1,2 and $0.2 \mu \mathrm{g} / \mathrm{mL}$, respectively. dSPE conditions: sample volume, $10 \mathrm{~mL}$ and $\mathrm{pH} 6$; $\mathrm{SiO}_{2} @ \mathrm{GO}$ particles $20 \mathrm{mg} ; 40^{\circ} \mathrm{C}$ ultrasound extraction for $40 \mathrm{~min}$; centrifugation at $9000 \mathrm{rpm} / \mathrm{min}$ for $5 \mathrm{~min} ; 100 \mu \mathrm{L} \mathrm{ACN} 40^{\circ} \mathrm{C}$ ultrasound back-extraction for $40 \mathrm{~min}$; centrifugation at $9000 \mathrm{rpm} / \mathrm{min}$ for $5 \mathrm{~min}$; HPLC-UV conditions: see Table 1, detected wavelength $230 \mathrm{~nm}$. developed dSPE with simple UV detection method demonstrated to be a simple, fast, cost-effective and eco-benign option for simultaneous determination of non-steroidal estrogens in some water samples.

\section{Conclusions}

In conclusion, a QuEChERS method for the determination of nonsteroidal estrogens in water samples was developed. The $\mathrm{SiO}_{2} @ \mathrm{GO}$ microspheres were firstly used as sorbent of dSPE and successfully applied to the extraction of three non-steroidal estrogens from different water samples. A wide linear range, low LODs, and good recoveries for three real samples indicated that the graphene oxide-coated-silica materials combined HPLC/UV method exhibits excellent extraction efficiency for the studied analytes under the optimal experimental conditions. The results obtained in our study indicated that graphene oxide has great potential for the preconcentration of estrogen analytes, and the proposed dSPE-HPLC method possessed advantages in respect of extraction efficiency, sensitivity and expenditure of sample treatment time.

\section{Acknowledgments}

Financial support from the National Natural Science Foundation of China (81460328, 21275158, and 21107057), the Colleges and Universities Scientific Research Projects of the Education Department of Hainan Province (HNKY2014-52), Research and Training Foundation of Hainan Medical University (HY2013-04 and HY2013-16) and the Natural Science Foundation of Hainan Province (414196) are gratefully acknowledged.

\section{References}

[1] P. Su, X. Zhang, W. Chang, Development and application of a multi-target immunoaffinity column for the selective extraction of natural estrogens from pregnant women's urine samples by capillary electrophoresis, J. Chromatogr. B 816 (2005) 7-14.

[2] L. Salste, P. Leskinen, M. Virta, L. Kronberg, Determination of estrogens and estrogenic activity in wastewater effluent by chemical analysis and the bioluminescent yeast assay, Sci. Total Environ. 378 (2007) 343-351.

[3] M. Kuster, M.J.L. de Alda, D. Barceló, Analysis and distribution of estrogens and progestogens in sewage sludge, soils and sediments, TrAC Trends Anal. Chem. 23 (2004) 790-798.

[4] D.L.D. Lima, C.P. Silva, M. Otero, V.I. Esteves, Low cost methodology for estrogens monitoring in water samples using dispersive liquid-liquid microextraction and HPLC with fluorescence detection, Talanta 115 (2013) 980-985.

[5] M.H. Liu, M.J. Li, B. Qiu, X. Chen, G.N. Chen, Synthesis and applications of diethylstilbestrol-based molecularly imprinted polymer-coated hollow fiber tube, Anal. Chim. Acta 663 (2010) 33-38.

[6] Z.X. Xu, J. Zhang, L. Cong, L. Meng, J.M. Song, J. Zhou, X.G. Qiao, Preparation and characterization of magnetic chitosan microsphere sorbent for separation and determination of environmental estrogens through SPE coupled with HPLC, J. Sep. Sci. 34 (2011) 46-52.

[7] Q.S. Zhong, Y.F. Hu, Y.L. Hu, G.K. Li, Dynamic liquid-liquid-solid microextraction based on molecularly imprinted polymer filaments on-line coupling to high performance liquid chromatography for direct analysis of estrogens in complex samples, J. Chromatogr. A 1241 (2012) 13-20.

[8] Y. Zou, Y.H. Li, H. Jin, H.N. Tang, D.Q. Zou, M.S. Liu, Y.L. Yang, Determination of estrogens in human urine by high-performance liquid chromatography/diode array detection with ultrasound-assisted cloud-point extraction, Anal. Biochem. 421 (2012) 378-384.

[9] Y. Yang, J.C.Y.P. Shi, Determination of diethylstilbestrol in milk using carbon nanotube-reinforced hollow fiber solid-phase microextraction combined with high-performance liquid chromatography, Talanta 97 (2012) 222-228.

[10] B. Socas-Rodriguez, M. Asensio-Ramos, J. Hernandez-Borges, M.A. RodriguezDelgado, Analysis of oestrogenic compounds in dairy products by hollow-fiber liquid-phase microextraction coupled to liquid chromatography, Food Chem. 149 (2014) 319-325.

[11] Y. Liu, N. Li, L.P. Ma, L. Huang, S. Jing, L.B. Zhao, W.Y. Feng, Determination of diethylstilbestrol in human plasma with measurement uncertainty estimation by liquid chromatography-tandem mass spectrometry, J. Liq. Chromatogr. Relat. Technol. 37 (2014) 353-366.

[12] C. Basheer, A. Jayaraman, M.K. Kee, S. Valiyaveettil, H.K. Lee, Polymer-coated hollow-fiber microextraction of estrogens in water samples with analysis by gas chromatography-mass spectrometry, J. Chromatogr. A 1100 (2005) $137-143$. 
[13] J.B. Quintana, J. Carpinteiro, I. Rodriguez, R.A. Lorenzo, A.M. Carro, R. Cela, Determination of natural and synthetic estrogens in water by gas chromatography with mass spectrometric detection, J. Chromatogr. A 1024 (2004) 177-185.

[14] Y. Guan, C. Jiang, C.F. Hu, L. Jia, Preparation of multi-walled carbon nanotube functionalized magnetic particles by sol-gel technology and its application in extraction of estrogens, Talanta 83 (2010) 337-343.

[15] Y.Y. Wen, J.H. Li, J.S. Liu, W.H. Lu, J.P. Ma, L.X. Chen, Dual-cloud point extraction coupled to hydrodynamic-electrokinetic two-step injection followed by micellar electrokinetic chromatography for simultaneous determination of trace phenolic estrogens in water sample, Anal. Bioanal. Chem. 405 (2013) 5843-5852.

[16] Y.G. Zhao, X.H. Chen, S.D. Pan, H. Zhu, H.Y. Shen, M.C. Jin, Simultaneous analysis of eight phenolic environmental estrogens in blood using dispersive micro-solid-phase extraction combined with ultra-fast liquid chromatography-tandem mass spectrometry, Talanta 115 (2013) 787-797.

[17] L.S. Hu, C.C. Fong, L. Zou, W.L. Wong, K.Y. Wong, R.S.S. Wu, M.S. Yang, Labelfree detection of endocrine disrupting chemicals by integrating a competitive binding assay with a piezoelectric ceramic resonator, Biosens. Bioelectron. 53 (2014) 406-413.

[18] S.Zhang, B. Du, H. Li, X.D. Xin, H.M. Ma, D. Wu, L.G. Yan, Q. Wei, Metal ions-based immunosensor for simultaneous determination of estradiol and diethylstilbestrol, Biosens. Bioelectron. 52 (2014) 225-231.

[19] C. Pouech, M. Tournier, N. Quignot, A. Kiss, L. Wiest, F. Lafay, M.M. FlamentWaton, E. Lemazurier, C. Cren-Olivé, Multi-residue analysis of free and conjugated hormones and endocrine disruptors in rat testis by QuEChERSbased extraction and LC-MS/MS, Anal. Bioanal. Chem. 402 (2012) 2777-2788

[20] F.F. Scherr, A.K. Sarmah, Simultaneous analysis of free and sulfo-conjugated steroid estrogens in artificial urine solution and agricultural soils by highperformance liquid chromatography, J. Environ. Sci. Health B 46 (2011) $763-772$.

[21] K.S. Novoselov, A.K. Geim, S.V. Morozov, D. Jiang, Y. Zhang, S.V. Dubonos, I.V. Grigorieva, A.A. Firsov, Electric field effect in atomically thin carbon films, Science 306 (2004) 666-669.

[22] K.P. Loh, Q.L. Bao, P.K. Ang, J.X. Yang, The chemistry of graphene, J. Mater. Chem. 20 (2010) 2277-2289.

[23] M.J. Allen, V.C. Tung, R.B. Kaner, Honeycomb carbon: a review of graphene, Chem. Rev. 110 (2010) 132-145.

[24] D.R. Dreyer, S. Park, C.W. Bielawski, R.S. Ruoff, The chemistry of graphene oxide, Chem. Soc. Rev. 39 (2010) 228-240.

[25] Y.B. Luo, Z.G. Shi, Q. Gao, Y.Q. Feng, Magnetic retrieval of graphene: extraction of sulfonamide antibiotics from environmental water samples, J. Chromatogr. A 1218 (2011) 1353-1358.

[26] Q. Liu, J.B. Shi, M.T. Cheng, G.L. Li, D. Cao, G.B. Jiang, Preparation of grapheneencapsulated magnetic microspheres for protein/peptide enrichment and MALDI-TOF MS analysis, Chem. Commun. 48 (2012) 1874-1876.
[27] W.N. Wang, Y.P. Li, Q.H. Wu, C. Wang, X.H. Zang, Z. Wang, Extraction of neonicotinoid insecticides from environmental water samples with magnetic graphene nanoparticles as adsorbent followed by determination with HPLC Anal. Methods 4 (2012) 766-772.

[28] W.B. Guan, Z.N. Li, H.Y. Zhang, H.J. Hong, N. Rebeyev, Y. Ye, Y.Q. Ma, Amine modified graphene as reversed-dispersive solid phase extraction materials combined with liquid chromatography-tandem mass spectrometry for pesticide multi-residue analysis in oil crops, J. Chromatogr. A 1286 (2013) 1-8.

[29] S.L. Zhang, Z. Du, G.K. Li, Layer-by-layer fabrication of chemical-bonded graphene coating for solid-phase microextraction, Anal. Chem. 83 (2011) 7531-7541.

[30] M.M. Tian, W. Feng, J.J. Ye, Q. Jia, Preparation of $\mathrm{Fe}_{3} \mathrm{O}_{4} @ \mathrm{TiO}_{2} /$ graphene oxide magnetic microspheres for microchip-based preconcentration of estrogens in milk and milk powder samples, Anal. Methods 5 (2013) 3984-3991.

[31] S.K. Sagiv, M.M. Gaudet, S.M. Eng, P.E. Abrahamson, S. Shantakumar, S.L. Teitelbaum, P. Bell, J.A. Thomas, A.I. Neugut, R.M. Santella, M.D. Gammon, Polycyclic aromatic hydrocarbon-DNA adducts and survival among women with breast cancer, Environ. Res. 109 (2009) 287-291.

[32] M. Anastassiades, S.J. Lehotay, D. Štajnbaher, F.J. Schenck, Fast and easy multiresidue method employing acetonitrile extraction/partitioning and "Dispersive Solid-Phase Extraction" for the determination of pesticide residues in produce (QuEChERS method), J. AOAC Int. 86 (2003) $412-431$.

[33] R. Su, X. Xu, X.H. Wang, D. Li, X.Y. Li, H.O. Zhang, A.M. Yu, Determination of organophosphorus pesticides in peanut oil by dispersive solid phase extraction gas chromatography-mass spectrometry, J. Chromatogr. B 879 (2011) 3423-3428.

[34] P.Y. Zhao, L. Wang, J.H. Luo, J.G. Li, C.P. Pan, Determination of pesticide residues in complex matrices using multi-walled carbon nanotubes as reversed-dispersive solid phase extraction sorbent, J. Sep. Sci. 35 (2012) $153-158$.

[35] A.V. Herrera-Herrera, L.M. Ravelo-Pérez, J. Hernández-Borges, M.M. Afonsob, J.A. Palenzuela, M. Rodríguez-Delgado, Oxidized multi-walled carbon nanotubes for the dispersive solid-phase extraction of quinolone antibiotics from water samples using capillary electrophoresis and large volume sample stacking with polarity switching, J. Chromatogr. A 1218 (2011) 5352-5361.

[36] W. Stober, A. Fink, E. Bohn, Controlled growth of monodisperse silica spheres in micron size range, J. Colloid Interface Sci. 26 (1968) 62-69.

[37] A. Walcarius, M. Etienne, J. Bessière, Rate of access to the binding sites in organically modified silicates. 1 . Amorphous silica gels grafted with amine or thiol groups, Chem. Mater. 14 (2002) 2757-2766.

[38] M. Clara, B. Strenn, E. Saracevic, N. Kreuzinger, Adsorption of bisphenol-A $17 \beta$-estradiole and $17 \alpha$-ethinylestradiole to sewage sludge, Chemosphere 56 (2004) 843-851. 